ऽ(タ)は零とみなせるので，表面層付近でのエントロピー密

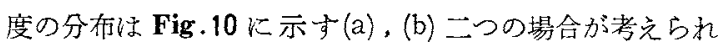
る。いずれの場合にも， $\Gamma=0$ の区分界面の位镇によって $s_{A(1)}$ は正負のいず梑もなりうるので, 本測定結果のよう に $s_{A(1)}$ が正の場合でも, この結果だけから表面層でのメ ントロピー密度が液体内部のそれより大きいそ結論するこ とはできない。

\section{IV. 結 論}

管径の異なる 2 本の毛管中に上昇した液体金属柱の高さ の比学的測定から表面張力を求める装置を製作し，スズ，
鎑の表面張力の測定を行ない，従来の測定法に比較して比 校的容易に再現性の良い繶果を得ることができた．表面張 力と温度との関係は次式で示される.

$$
\begin{array}{ll}
\gamma_{\mathrm{Sn}}=587.8-0.056 \times t\left({ }^{\circ} \mathrm{C}\right) & \text { dyne } / \mathrm{cm} \\
\gamma_{\mathrm{Pb}}=497.6-0.087 \times t\left({ }^{\circ} \mathrm{C}\right) & \text { dyne } / \mathrm{cm}
\end{array}
$$

本研究々同一のスズ試料，同一水素ガス需团気中での静滴 法による表面張力の湘定結果は, 本測定結果とよく一致し た. スズ，鉛の表面張力の従来の湘定結果の比較から，測 定雾围気の相違によって表面涱力の温度保数に，明らかな 相違のあることを指摘した。

\title{
$25 \mathrm{keV}$ 程度の電子線に対する複合標的における 表面膜の「等価膜厭」の算定*
}

\section{正藤和 男* 壬木栄次**}

Kazuo Masato and Eiji Niki : Computation of "Equivalent Thickness" of Surface Films in Composite Targetes for about $25 \mathrm{keV}$ Electrons. An experimental method for the determination of mass absorption coefficients for the very soft X-ray region by use of EPMA and a composite target, prepared by evaporating a film of metal of different atomic numbers over a base layer, has been devised. In the method it is necessary to know the "equivalent thickness", i.e.the thickness of the surface film, which satisfies the assumption that the characteristic X-ray intensities from backing materials in the composite targets under the surface films are equal to each other. A method of calculation for the "equivalent thickness" is proposed in this work.

The "equivalent thickness" is calculated with the aids of Cosslett and Thomass' expression for the energy distribution of incident electrons in a solid target, and equations for the total electron transmission, for the backscattering coefficients of an isolated film and a massive target, and for the mean energy of electrons transmitted through and backscattered from the isolated film and massive target. The values for the "equivalent thickness" of all elements from $Z=12$ to $Z=92$ are computed by use of these equations.

(Received September 11, 1972)

\section{I. 緒喜}

X線マイクロアナライザ(EPMA)で金属中の超軽元素を 定量分析する祭，信頼し得る質量四収保数の不足あるいは 不確定性を痛感する。現在，原子番号 11 番以上の元素の 特性X線，すなわち波長約 $12 \AA$ 以下のX線に対する質量 吸收保数は，全吸收体元素について，注湾確定さ礼てきた

\footnotetext{
** 㫧京大学守宙航空研究所 (Institute of Space and Aeronautical Science, University of Tokyo, Tokyo)

* 1972年4月金属学会東京大会敒表; $12 \AA$ 以上の X線の筫量吸収係数に関する研究(第 1 報)

(1) B.L.Henke, R. White and B.Lundberg: J.Appl. Phys., 28 (1957) , 98.

(2) B.A.Cooke and E. A. Stewardson: Brit. J.Appl. Phys., $15(1964), 1315$.

(3) W.T. Ogier, G. J. Lucas and R. J.Park: Appl. Phys.Letters, $5(1964), 146$.

(4) A.J.Bearden : J.Appl.Phys., 37 (1966), 1681.
}

が，これより低い原子番号の元素の特性X線に対する質量 吸収係数は，必ずしも確定的ではないと思われる。近時, これらの長波長の，いわ和る欶〜超軟X線の質量吸収係数 についての研究は，笑駼的にあるいは理諭的に，一部亦た は全部の吸收体元素についてなされてきてはいるが(1) (9), これらの值は，元素の $K$ まは $L$ 吸叹端波長が，対象と

(5) E.Kohthaas und F.Scheiding:Vth Int.Cong.on $X$-Ray Optics and Microanalysis, Tubingen, (1968), 193.

(6) R.D.Dewey : Handbook of X-Ray and Microprobe Data, Pergamon Press, (1969), 307.

（7）正藤和男, 仁朴栄次：金属学会講演概要, (1970.4), 90 .

（8）大平五郎, 渡辺 融, 名和田隆治: 金属学会講演概 要 $(1971.4), 138$.

(9) W. J.Veigele, E. Bringgs, B. Bracewell and M. Donaldson : Electron Probe Microanalysis, by L.S. Birks,2 nd Ed., Willey-Interscience, (1971), 147. 
するX線波長より長い場合は良いが，短かい照合は相互に 川成りの違いがあるものが多い，たと充ば，C Ka 線の質 量吸收係数として与光られている值は，Feに対して，最高 值 ${ }^{(9)}$ と最底值 ${ }^{(5)} て ゙ 10$ 倍の遠いがある。Wに詨しては実に 20 倍以上の違いがある。

そこで䇠者は，EPMA と特殊なターゲット(ベースと表 面膜とから成る複合ターゲット)学使って测定する。一種の 閐接測定法を考案したが，この方法を確立するためには， 後述するような意味の「エネルギー的に等洒」な表面膜層 の厚され知る必要がある。

\section{II． 本測定法の骨子とその理論的考察}

この力法は，前述の複合ターゲットを試料とするわけて あるが，対象と寸る特性X線源をべースとして種令な吸収 体薄荧を蒸着し，これを試料として EPMA に装着し，電 子線の入射電正拈よび䉓流を一定として，べースの対象と する特性 X線強度を浿定する。

このとき湘定される対象X線は，当然，膜層による吸収 を受けているが，同時汇，電子線の入射過程に扎いても， すなわち, X線の発生過程に扎いても, 複雑な影響を受 け，その合成された結策が浿定されるわけである。しかし 結論として，もしべースの対象とする特性X線強度，すな わち慕に入射する対象X線強度が，膜の種類(元素と厚さ の組合せ）によって相互に等しくなる条件があれば，後述 の上うにして，対象とするX線に対する荧物質の質量吸収 係数を決定することがでさる。

膜に入射する対象X線は（i)べースに吸収された電子線 によって，1次的に発生するX線と，(ii)膜に吸収されたた電 子線に上って発生した，膜の特性X線のべース吸収分によ って，2次的比発生するX線を含む．もち万九，この他仡 (iii) 捙続X線によるものもある.

ここで，(i)は直接イオン化数江関する問題であるからべ 一スに吸收される電子線エネルギーが等しければ等しい， と仮定してよいと考兄ら狆るが，(ii)と(iii)で問題となる のは，全イオン化数に詨する間接イオン化数の割合 $S$ ， 膜の物質による変化である。しかし，ここで詨象とするよ らな非常に軟いX線に関する限りＳそのものが非常に小 さいので無視できる。結局(i)が支配的である、寸なわち 最初の電子線エネルギーを一定にすることと、ベース炕 收される電子線エネルギーが等しい膜厚と物質の組合せを 選ぶことが，そのとき㯖の直下で発生する＝膜に入射す る対象X線強度が相Tに等しい，と仮定できる条件を作る ことになる。

今, 厚さ $t_{1}\left(\mathrm{~g} / \mathrm{cm}^{2}\right)$ (以下 $t$ は mass thickness)なる物貿 1 の㮠を考乓ると，测定される対象X線強度 $I_{1}$ は，そのと

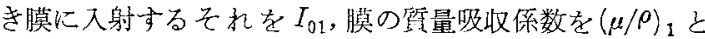
すると

$$
I_{1}=I_{01} \exp \left[-\left(\frac{\mu}{\rho}\right)_{1} t_{1} \csc \theta\right]
$$

ただし $\theta$ は取低し角である，同様に他の物質 2 の膜を考秃 ると,

$$
I_{2}=I_{02} \exp \left[-\left(-\frac{\mu}{\rho}\right)_{2} t_{2} \csc \theta\right]
$$

W 穴，

$$
\ln \frac{I_{1}}{I_{2}}=\ln \frac{I_{01}}{I_{02}}+\left\{\left(-\frac{\mu}{\rho}\right)_{2} \frac{t_{2}}{t_{1}}-\left(\frac{\mu}{\rho}\right)_{1}\right\} t_{1} \csc \theta(1)
$$

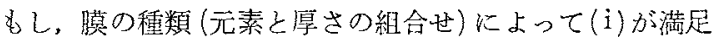
される条件があれば，その条件下では $I_{01}=I_{02}$ となるから (1)式右辺の第 1 項は 0 となり,

$$
\ln \frac{I_{1}}{I_{2}}=\left\{\left(\frac{\mu}{\rho}\right)_{2} \frac{t_{2}}{t_{1}}-\left(\frac{\mu}{\rho}\right)_{1}\right\} t_{1} \csc \theta
$$

その一つの形として

$$
\frac{\ln \frac{I_{1}}{I_{2}}}{t_{1} \csc \theta}=\left(\frac{\mu}{\rho}\right)_{2} \frac{t_{2}}{t_{1}}-\left(\frac{\mu}{\rho}\right)_{1}
$$

すなわち，厚さ $t_{1}$ なる物質 1 の薄膜を表面慕とする複合 ターゲットから湘定された，べースの特性X線強度と，厚 さ $t_{2}$ なる物質 2 の薄膜を表面膜とする複合夕ーゲットか ら測定されたべースの特性X線強度の比 $I_{1} / I_{2}$ の対数を， $t_{1}$ なたは $t_{1} \csc \theta て ゙$ 割って， $t_{2} / t_{1}$ の関数としてプロットす れば直線となり，その勾配と切片から，両力の慕の物䁈の 質量吸收保数を決定できる。

その条件とは，すでに詳述したように，べースに吸収さ れる電子線エネルギーが相互に等しいことが仮定できる， 表面膜の物質と厚さの組含せを選ぶことに深かならない。 なお，この薄膜の厚さを「エネルギ一的化等価な表面膜 学」と仮称し，しばしば，能に「等価联厚」と略記する。

\section{III.「等価膜厚」の計算}

Cosslett そ Thomas ${ }^{(10)}$ 比上れば，固体ターダッ卜にお いて，表面から深さ $t$ のところに界面を仮想したときこ の仮想界面から上の層に吸收されるエネルギー $E_{A}$ は，

$$
E_{A}=E_{0}-\eta_{T} E_{m T} \frac{1-r \frac{E_{m R}}{E_{0}}}{1-r \eta_{B} \frac{E_{m R} E_{m B}}{E_{0}^{2}}}-r E_{m R}
$$

ここで $E_{0}$ は入射電子線のエネルギー， $\eta_{T}$ と斿は厚さ $t$ の 層だけを考えたとさにこの層を透過あるいは反射する電流 の割合, $E_{m B}$ 之 $E_{m R}$ は層の夕市るい性全体からの後方散乱電子の， それぞれ平均エネルギーである，そこで（4)式の右辺第 2 項㤝 $t$ から下の部分に吸収される，第 3 項は全体から反 射される，それ卆机亦ルギ一である。

いま，この層を厚さ $t$ の他の物質の膜で置き換え，上の 説明の「層」を「膜」「バルク」を「ベース」と読子替え ると，膜より下の部分(=ベース)に吸収されるエネルギー $E_{s}$ は

(10) V.E. Cosslett and R. N. Thomas: Brit. J. Appl. Phys., $16(1965), 779$. 
である。

$$
E_{s}=\eta_{T} E_{m T} \frac{1-r \frac{E_{m R}}{E_{0}}}{1-r \eta_{B} \frac{E_{m R} E_{m B}}{E_{0}^{2}}}
$$

したがって，種々な物質の表面膜をもつ複合ターダット について， $E_{s}$ が等しくなるよらな表面償厚二「等価慕厚」 を計算することができる。

\section{IV. $\eta_{T}, \eta_{B}, \boldsymbol{r}, \boldsymbol{E}_{m T}, \boldsymbol{E}_{m B}$ および $\boldsymbol{E}_{m R}$ の計算}

\section{1，電子線の透過}

Bothe ${ }^{(1)}$ の統計理:满によれば，入射電子線の方问を中心 線として，頂伯 $2 \phi(\mathrm{rad})$ の円錐の中に集められる透過電流 の割合 $\eta_{\text {は }}$ ，透過電子の件度分布が 2 次元的にはガウス 分布に従らとして，次式で与党られる。

$$
\eta_{, j}=1-\exp \left(\frac{-\phi^{2}}{2 \lambda_{B}^{2}}\right)
$$

ここで $\lambda_{B}$ は全散乱汇ついての曼多散乱伯 (most probable angle)で, Cosslett ら (12)の表現に従えば,

$$
\lambda_{B}^{2}=\left(\frac{4 Z}{E_{0}}\right)^{2} \frac{\rho_{x}}{A} \times 10^{10}
$$

である。 $\rho$ は密度， $x$ は透過距篗

一方,多重散乱に関する BRS (Bethe, Rose 拉よび Smith) の理渝(13) によれば, 全透過電流の割合 $\eta_{T}$ は に大きいとを

$$
\eta_{T}=\frac{0.862}{\frac{x}{\lambda}+0.719}
$$

ここで入は transport mean free path で

$$
\frac{1}{\rho \lambda^{-}}=\frac{\pi e^{4} N Z^{2}}{2 A E_{0}^{2}} \ln -\frac{E_{0}^{1 / 2}}{2 Z^{1 / 3}}
$$

$e$ は電子の電荷, $N$ はアボガドロ数である. それぞれの数 俌を入れると, (7) 式の䇥数部分 $\pi e^{4} N / 2$ は $1.96 \times 10^{10}$ と なる。

しかし $\mathrm{Cu}$ と Au の膜について湘定した赛験值は, Bothe の式にも BRS の式纪多いずれの式にも一致せず(12)，1 次 近但としては同程度に合う。皇こで基本式として(6)式を とりこれを修正することにした。

今 $x=n t / \rho$ とすると，(6)式は次のよらに書ける。

$$
\eta_{T}=\frac{0.862}{\frac{n t}{\rho \lambda}+0.719}
$$

实駼值か (8)式と一致するとして $n$ を計算し， $t$ の関数と してプロットすると Fig.1(後述の結果も垪記)の“穼駼值” の上うになり，近似的に次式で表現できる。

$$
n=A t^{C}+B t^{-D}
$$

(11) W. Bothe : Handbuch der Physik, 22/2, Julius Springer, Berlin, (1933) , 1 .

(12) V.E.Cosslett and R. N. Thomas : Brit. J. Appl. Phys., 15 (1964), 883.

(13) H. A. Bethe, M. F. Rose and L. D. Smith : Proc. Amer. Soc., 78 (1938) , 573.

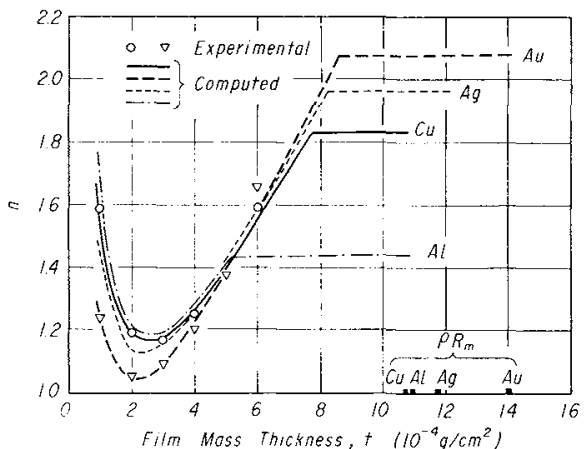

Fig.1 Value of $n$ as a function of film mass thickness $E_{0}=25 \mathrm{eV}$

ただし $れ 、 1 \times 10^{-4}$ の範囲とする。束た $t \geqq 2.5 \times 10^{-4}$ で は $n_{R}$ (後述)を超えることはない，A, $B, C, D$ はそれぞれ $Z$ と $E_{0}$ によって定まり， $E_{0}$ を一定と守礼ば $Z$ のみの関数 となる。この関数の形は明らかでないが，あまり大きな变

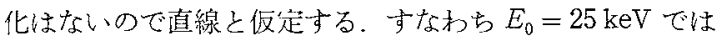

$$
\begin{aligned}
& A=0.313-0.001 Z \\
& B=1.474-0.006 Z \\
& C=0.7877+0.0024 Z \\
& D=1.0734-0.0036 Z
\end{aligned}
$$

$n_{R}=R_{B} / R_{m}$ で, $R_{B}$ は理諭的(あるいは真の)飛程であり， $R_{m}$ は乞それ相当する实際の厚さである。

Bethe (14) の理論から導加るよらに, 電子線の平坞工 ネルギーが $J / 2$ ( $J$ は平均イオン化エネルギー)に減哀する

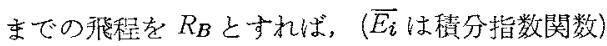

$$
\rho R_{B}=\frac{J^{2} A}{8 \pi e^{4} N Z} \overline{E_{i}}\left(2 \ln \frac{2 E_{0}}{J}\right)
$$

ここで $J=11.5 Z$ とすると，

$$
\rho R_{B}=4.21 \times 10^{-10} A Z \overline{E_{i}}\left(2 \ln \frac{0.174}{Z} E_{0}\right)
$$

一方 $R_{m}$ は Cosslett らの修正したTW 則 (ThomsonWhidington の法則) (12) によって,

$$
\rho R_{m}=\frac{E_{0}^{2}-\left(\frac{J}{2}\right)^{2}}{\frac{b}{\rho}}
$$

$b / \rho$ は透過電子の平均エネルギーの減衰を TW 則の形に表 現したときのエネルギー損失パラメータで，次のように考 える。

$$
\frac{b}{\rho}=\frac{E_{0}^{2}-\left(\frac{J}{2}\right)^{2}}{\rho R_{B}}+\Delta \frac{b}{\rho}
$$

右辺第 1 項は Bethe の理論から期待される $b / \rho$ に他ならな

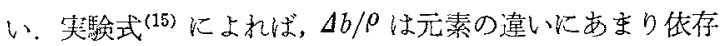
せずほ滛一定であるが，前述したように $R_{B} と R_{m}$ の差を 真の行程と实祭の愿さの差とするならば， $\Delta b$ は平约散乱

(14) H. A. Bethe : Handbuch der Physit, 24, Julius Springer, Berlin, (1933), 519.

(15) V.E. Cossiett and R. N. Thomas : Brit. J. Appl. Phys., 15(1964), 1283. 
传や $n_{R}$ に依存する筈であるからZに依存することにな る，以上の洘察加ら $A b / P$ 限られたZ範阱について近似

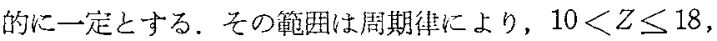
$18<Z \leq 36,36<Z \leq 54,54<Z \leq 86$ 拉よび $86<Z$ の

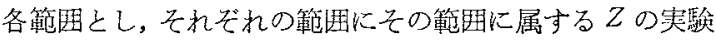
值を使う。すなわら $\Delta b / 0$ の值としてそれぞれ 17.4169

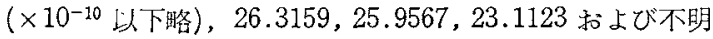
である，不明の部分は上の考察をらまえて，前の範囲の値 を採用する。

透過電子の平均エネルギー $E_{m} T$ は Cosslett らの修正し たT 則

$$
E_{0}^{2}-E_{m T}^{2}=\frac{b}{\rho} t
$$

による。

\section{2. 電子線の反射}

後方散乱係数 $r$ の理墖式としては，今までに次の諸式が 与えられている。

$$
\begin{gathered}
r_{A}=\frac{7 Z-80}{14 Z-80} \\
r_{c}=\frac{Z-16}{2 Z-8} \\
r_{E}=\frac{a-1+0.5^{a}}{a+1}, a=0.045 Z
\end{gathered}
$$

(15) 式は Archard(16) の式である。彼の理馀によれば，入 射電子はある深さ $x_{d}$ 妾で直進し，そこで全方向以均一に 散乱(すなわり払散)することになり，大你単一散乱が無視 されている。この 正したTomlin の式(12)に求めると， $r$ として(16)式となる. (17)式はEverhart(17)の式で，弾性衝突の理論によってい るが，多重散乱の効果を無視している。はたしてこれらの 式は，いずれも，多くの研究者の実駼值 ${ }^{(18)(19) \sim(23)(26)(27)}$ と 完全には一致しない(Fig.2 参照)。しかし(17)式の $r_{E}$ と 実験値との差の大きさは，主として多重衝突の機会の多少 にかかわると考光られるから，Zに佛存する。この上らな 考察から，できるだけ簡単な式で実験值と合らように(17) 式を修正すると次式のようになる。

$$
r=r_{E}-0.0014|Z-27|
$$

膜のみの後方散乱係数 $\eta_{B}$ については, Everhart の理論 の拡張から

$$
\eta_{B E}=\frac{a-1+(1-y)^{a}(2 a y+1-a)}{a+1}, y=\frac{x}{R}
$$

(16) G.D.Archard: J.Appl.Phys., 32(1961), 1505

(17) T.E.Everhart: J.Appl.Phys., 31(1960), 1483.

(18) J.E.Holliday and E.J.Sternglass : J.Appl.Phys., $28(1957), 1189$.

(19) B.F.J.Schonland : Proc.Roy.Soc, (London), A 108 (1925) , 187

(20) H.Kanter : Ann. Physik, 20(1957), 144.

(21) H. E. Bishop: IVth Int. Cong.X-Ray Optics and Microanalysis, Hermann, Paris, (1966), 153.

(22) K.F.J. Heinrich : IVth Int. Cong. X-Ray Optics and Microanalysis, Hermann, Paris, (1966), 159.
を得る ${ }^{(24)}$ が，実験偡との関係が複雑なため，これまでの よらな理論式を修正するといら立場をすてた。

実験值 ${ }^{(24)(25)}$ の $\eta_{B} / r$ を $y$ の関数としてプロットすると

Fig.3のようになり， $Z \leq 28$ と $Z \geq 29$ とで明らかた異な

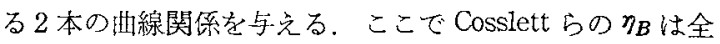
電流の割合であり,Kulenkampff らの $\eta_{B} /$ は $117^{\circ}$ と $137^{\circ}$ での測定である(ここではその平均を用いた）ただし $y=$ $t / \rho R_{m}$ とする。

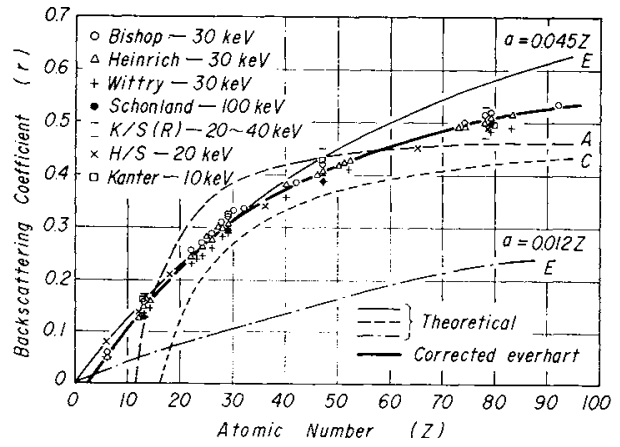

Fig.2 Comparision of the experimental data and corrected Everhart's for backscattering coefficients of massive targets with theoretical curves of Archard(A), Cosslett's $A(C)$ and Everhart $(E)$

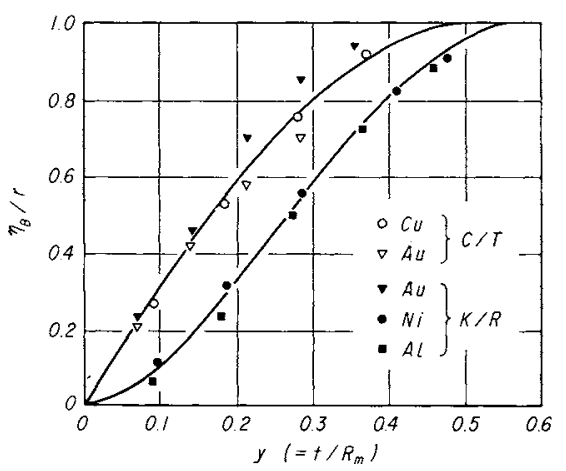

Fig.3 Experimental data for $\eta_{\mathrm{B}} / r$ as a function of $y . \quad E_{0}=25 \mathrm{keV}$

$C / T$ : Cosslett and Thomas

$K / R$ : Kulenkampff and Rüttiger

ゆ完に

$$
\left.\begin{array}{ll}
\eta_{B}=r P(y) & (Z \leq 28) \\
\eta_{B}=r Q(y) & (Z \geq 29)
\end{array}\right\}
$$

関数 $P(y)$ および $Q(y)$ は後出の $F(t)$ とともに, ラグラン ジの方法で数值計算する.

(23) D.B.Wittry : IV th Int. Cong. X-Ray Optics and Microanalysis, Hermann, Paris, (1966), 168.

(24) V.E. Cosslett and R.N. Thomas: Brit. J. Appl. Phys., 16(1965), 779.

(25) H. Kulenkampff und K. Rüttiger : Z. Phys., 152 (1958), 249.

(26) H. Kulenkampff und W. Spyra : Z. Phys,, 137 (1954), 416.

(27) H. Kulenkampff und K. Rüttiger : Z. Phys,, 137 (1954), 426 . 


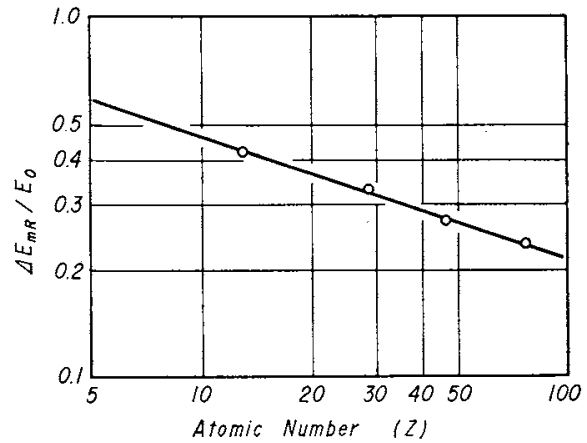

Fig.4 Experimental data of Kulenkampff and Rüttiger on $\Delta E_{m R} / E_{0}$ as a function of atomic number. $E_{0}=20$ to $40 \mathrm{keV}$

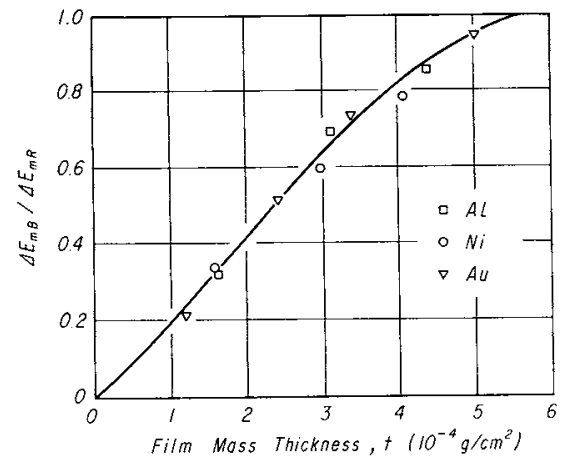

Fig. 5 Experimental data of Kulenkampff and Rüttiger on $\Delta E_{m B} / \Delta E_{m R}$ as a function of film mass thickness. $E_{0}=20$ to $40 \mathrm{keV}$

後方散乱電子の平均エネルギー $E_{m R}$ 岕よび $E_{m B}$ につい ての理論式は見当らないが，実験的には $\left(E_{0}=20 \sim 40 \mathrm{keV}\right.$ における Kulenkampff ら ${ }^{(25) \sim(27)}$ の実験)次式で与えられ る(Fig.4 柇よび Fig.5 参照).

$$
\begin{gathered}
\frac{\Delta E_{m R}}{E_{0}}=Z^{-1 / 3} \\
\frac{\Delta E_{m B}}{E_{0}}=\frac{\Delta E_{m R}}{E_{0}} F(t)
\end{gathered}
$$

ここで $\Delta E_{m}=E_{0}-E_{m}$ である.

\section{V. 計 算 結 果}

\section{1. $\eta_{T}$}

(11) 式から $R_{B}$ ，これと(12)，(13) 式から $R_{m}$ を計算して， $n_{R}$ を求め, これを一方の限界としながら，(9)，(10) 式から $n$ を計算し，(7)式ととあに(8)式に入れて文得る。 $E_{0}=25 \mathrm{keV} に お け る \eta_{T}$ の計算絬果を $Z$ を横軸に， $t$ を分 ラメータとしてプロットすればFig.6の通りである。なお 比較のために, Bothe 扢よび BRS の理論值为併記した.

\section{2. $r$}

(18)式の計算值を実験値および他の理論值ととむに Fig.2 に示す.

\section{3. $\eta_{B}$}

(19) 式の計算值の一部を実駼値とともに Fig.7 に示す.

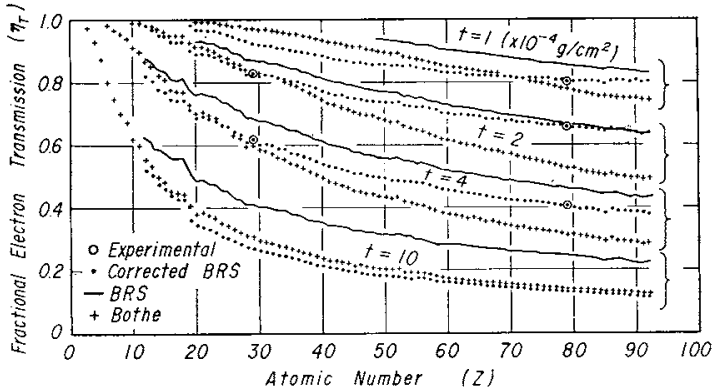

Fig. 6 Comparision of experimental data of Cosslett and 'Thomass and corrected BRS' data for fractional electron transmission with theoretical values of Bethe, Rose and Smith (BRS) and Bothe. $E_{0}=25 \mathrm{keV}$

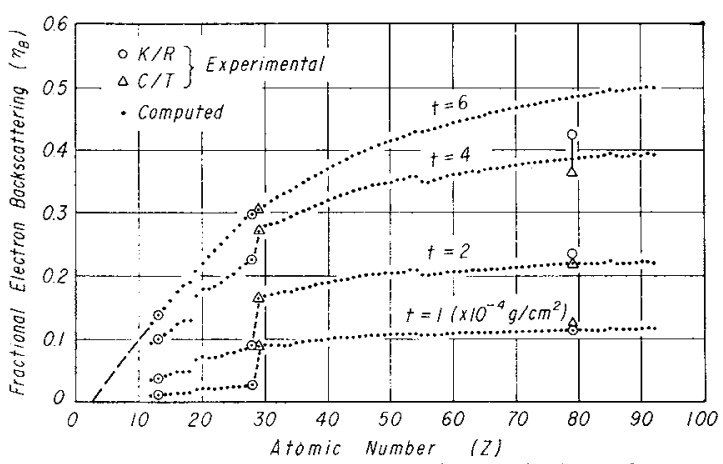

Fig.7 Comparision of experimental data for fractional electron backscattering from film with computed results. $E_{0}=25 \mathrm{keV}$

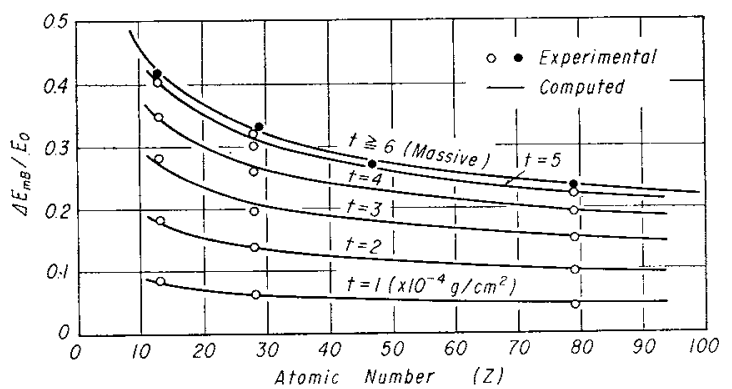

Fig.8 Comparision of experimental data of Kulenkampff and Rüttiger on $\Delta E_{m B} / E_{0}$ with computed results as a function of atomic number. $E_{0}=20$ to $40 \mathrm{keV}$

4. $\Delta \boldsymbol{E}_{m R} / \boldsymbol{E}_{0}$ および $\Delta \boldsymbol{E}_{m B} / \boldsymbol{E}_{0}$

(20) 式と(21) 式による計算值の一部を実験值とともに Fig.8に示す。

\section{5. $\boldsymbol{E}_{m T}$}

図示省略.

\section{6. $E_{s}$}

IV .2に述べた定義により， $E_{m} / E_{0}=1-\left(\Delta E_{m} / E_{0}\right), E_{m}=$ $\left\{1-\left(\Delta E_{m} / E_{0}\right)\right\} E_{0}$ であるから，(5)式は次のように書け る. 


$$
E_{s}=\eta_{T} E_{m T} \frac{1-r\left(1-\frac{\Delta E_{m R}}{E_{0}}\right)}{1-r \eta_{B}\left(1-\frac{\Delta E_{m R}}{E_{0}}\right)\left(1-\frac{\Delta E_{m B}}{E_{0}}\right)}
$$

この式と(7)〜(14)和よび(18)〜(21)式とから計算した $E_{s}$ の值の一部を Fig.9に示す．Fig.9はベースがCu の場 合で，対象とするX線は $\mathrm{Cu} L \alpha$ である。この他対象X線が $\mathrm{O} K \alpha ， \mathrm{C} K \alpha$ の場合も計算したが結果の図示は省略する。

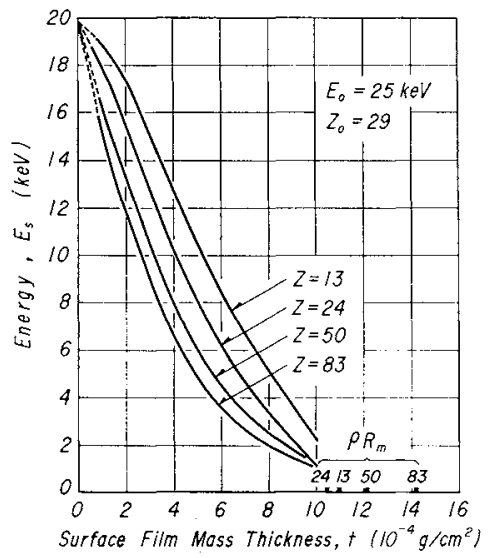

Fig.9 Computed results for $E_{s}$ as a function of surface film mass thickness. $E_{0}$ : incident energy of elctrons, $Z_{0}:$ atomic number of backing material, $Z$ : atomic number of surface film

\section{7. 「等価膜厚」}

Fig.9で， $E$ 軸上のある点において $t$ 軸に平行に引いた 直線之, 各 $Z$ についての $E_{s}$ 曲線との交点加 $t$ 軸に下し た垂線の足が，たがいに「等価膜厚」となる。一般に，原
Table 1 Examples of computed "equivalent thickness". $Z_{0}=6, E_{0}=25 \mathrm{keV}$

\begin{tabular}{c|c|c|c|c|c}
\hline $\begin{array}{c}\text { Atomic No. of } \\
\text { surface film }\end{array}$ & \multicolumn{5}{|c}{$\begin{array}{c}\text { Surface film mass thickness } \\
\left(10^{-4} \mathrm{~g} / \mathrm{cm}^{2}\right)\end{array}$} \\
\hline 13 & 1.000 & 2.000 & 3.000 & 4.000 & 5.000 \\
12 & 0.981 & 2.020 & 3.042 & 4.041 & 5.036 \\
20 & & 1.351 & 2.224 & 3.106 & 3.979 \\
30 & & 0.972 & 1.870 & 2.725 & 3.572 \\
40 & & & 1.592 & 2.418 & 3.233 \\
50 & & & 1.399 & 2.196 & 2.981 \\
60 & & & 1.241 & 2.014 & 2.773 \\
70 & & & 1.149 & 1.889 & 2.622 \\
80 & & & 1.073 & 1.778 & 2.483 \\
90 & & & 1.051 & 1.726 & 2.408 \\
92 & & & 1.046 & 1.716 & 2.392 \\
\hline
\end{tabular}

子番号 $k$, 原子量 $u$ の元素の厚さ $h$ の膜に対する, 原子番 号 $l$ 原子量 $v$ 元素の「等価膜厚」 $\left(\mathrm{g} / \mathrm{cm}^{2}\right)$ は, $Z=k, A=$ $u, t=\rho h$ として $E_{s}$ 老計算し，これを $E$ とするとき， $E_{s}=$ $E, Z=l, A=v$ として(7) (14)および (18) 〜 (22) 式を同時 に満足するtの值として計算した，結果の一部を Table 1 に示す。

\section{VI. 総括}

EPMA と特殊なターダットを使って，非常に軟いX線 の質量吸収係数を測定する方法を考案し，この力法に必要 な「等估膜厚」を算定する方法を確立した。

固体ターゲットに却忷る電子線エネルギーの分布に関す る Cosslett とThomas の式を援用し，この式の計算に必 要なすべての值を求める式を立て，これらの式を使い，電 子計算機によって原子番号 12 から 92 までの全元素につい て計算した(結果は一部のみ示寸)。 